\title{
The Implementation of Social Skills Training (SST) to Improve the Social Skills of an Adolescent with Peer Relationship Problems at School
}

\author{
Marcelina M.D. Tetono ${ }^{a}$, Ike Anggraika Kuntoro ${ }^{\text {b*and Luh S.Y. Savitri }}{ }^{b}$ \\ ${ }^{a}$ Faculty of Psychology, Universitas Indonesia, Depok, Indonesia, ${ }^{b}$ Department of \\ Developmental Psychology, Faculty of Psychology, Universitas Indonesia, Depok, \\ *Corresponding Author: \\ Ike Anggraika Kuntoro \\ Developmental Psychology Department \\ Faculty of Psychology, Universitas Indonesia \\ J1. Lkr. Kampus Raya, Depok, Jawa Barat \\ Indonesia, 16424 \\ Tel.: +62 217270004 \\ E-mail: ike.anggraika@ui.ac.id
}




\title{
The Implementation of Social Skills Training (SST) to Improve the Social Skills of an Adolescent with Peer Relationship Problems at School
}

\begin{abstract}
Having a good relationship with one's peers is important for adolescents because it influences their self-perception. To establish a positive relationship with peers, good social skills are essential. Therefore, adolescents with social skill deficits require intervention. This study uses pre- and post-test design to examine the effectiveness of Social Skills Training (SST) implementation to improve social skills in adolescents who have peer relationship problems at school. The participant in this study was a 14year-old girl with social skill deficits. SST was conducted in eight sessions lasting 30 60 minutes each. In this study, teachers and friends were included to assess and evaluate the participant's social skills. The subject's increased social behavior as a component of social skills was assessed by using teachers' observation and interview. The results indicate an increase in social skills in terms of the target behavior. Based on the Child's Behavior Checklist, scores in the social competence subscale increased. Meanwhile, based on the Social Skill Questionnaire, the total social skill score, along with social behavior, social perception, self-regulation, and social problem-solving scores also increased. Her peers and teachers also reported improvements in the subject's emotion regulation and social behavior. Furthermore, based on the SelfPerception Profile for Adolescent, social competence, physical appearance, close friendship, and the global self-esteem subdomains also showed an increase.
\end{abstract}

Keywords: adolescent; social skills; peer relationship; Social Skills Training

\section{Introduction}

To interact with the social environment, an adolescent must have good social skills, which is an essential ability to successfully interact with others (Spence \& Donovan, 1998). An adolescent must be socially involved with peers, because peers serve as the main social support in addition to one's family. Relationships with peers help adolescents interact with familiar figures, especially those whom teenagers spend a lot of time and do activities together with (Gottman \& Parker, 1987). Peers are really influential for teenagers, especially because the latter use most of their time to interact and engage in activities with the former.

Indeed, social support from peers is one the most important factor in establishing one's selfconcept (Furman \& Buhrmester, 1992; see also Santrock 2014; Papalia \& Martorell, 2014). Adolescents obtain feedbacks about their social ability, which they then use to compare themselves with their peers (Santrock, 2014). In turn, such feedbacks are necessary for developing self-perception. Positive feedbacks from peers could become positive self-perception. Self-perception is developed by how someone perceives themselves, including the skills or achievement that they have attained in various aspects of life. For teenagers, the components of self-perception which are related to peer relationship, include social competences, physical appearance, relationship with close friends, and global self-esteem (Harter, 2012). In this intervention, self-perception is measured as it has a close relationship with the participant's problem and is one of the sub-component of social skills according to Spence (2003). 
Peer interaction is also a great motivation for teenagers to actively participate in activities that pique their interests at school (Wentzel, McNamara \& Caldwell, 2004). A positive relationship with peers can motivate teenagers to be involved in academic activities at school. In turn, teenagers who are highly motivated to go to school are more likely to actively participate in a variety of activities, such as academic or extracurricular activities. Through those activities, they can learn new skills and knowledge, so that they can master specific competencies or show great academic achievement. Caprara, Barbaranelli, Pastorelli, Bandura, and Zimbardo (2000) pointed out that students with adequate social skills have high motivation to come to school and display greater eagerness to explore numerous school activities, which in turn, can help improve certain skills and increase their academic achievements.

In general, there are three social skills components that are important for adolescents. The first component is communication with peers. Verbal and nonverbal communication comprise one of the main components of social skills that teenagers must be able to master (Haager \& Vaughn, 1995; Sugai \& Lewis, 1996; Kolb \& Hanley-Maxwell, 2003). Verbal communication encompasses all forms of oral communication, whereas nonverbal communication includes all forms of communication done by using one's body language. Teenagers are better able to convey their thoughts and feelings if they have good communication skills. If other people can receive their thoughts and feelings well, then a positive reciprocal communication is expected.

The second social skills component is peer adjustment. According to Kingery, Erdley, and Marshall (2011), there exists a correlation between peer acceptance and adjustment at school. Adolescents who feel accepted by peers do not feel lonely and are better adjusted in their academics. The final component is social problem solving. The adolescents' ability to solve problems improves rapidly during this time, as they become more exposed to various situations that need to be solved independently, such as problems in friendship (Bulkeley, 1991). These three social skills components are important in constructing a harmonious long-term relationship with friends.

Apart from those mentioned above, having relationships with peers is also critical for adolescents because of its role in increasing one's negotiation skills while facing problems within a school environment (Steinberg, 2008). Negotiation skills are essential for someone to be able to meet the interests of all parties, social demands, and their own needs. Negotiation skills also enable someone to achieve conflict resolution. Teenagers who are able to resolve conflicts with peers are better able to develop a positive relationship with them. Such a positive relationship with friends is related to social acceptance, which in turn, is fundamental during adolescence. Kingery et al. (2011) recruited 365 middle school students in the US and found that positive relationship with friends determines peer acceptance, which can be discerned through the opportunities given by friends to be included in activities held together.

Teenagers with better social skills tend to have more positive self-perception (Mize, 2005), which is related to academic achievement (Caprara, et al., 2000). Social skills are important in preparing teenagers to have certain fundamental skills needed during adulthood, such as establishing a good relationship with their surroundings, gaining mastery of certain skills, and performing well in the academic field (Ingersoll, 1989 as cited in Ten Dam \& Volman, 2007).

Meanwhile, teenagers who are socially inept tend to experience more distress and anxiety. According to LaGreca and Harisson (2005), teenagers who have a poor relationship with peers 
are more likely to experience distress in their social life, as a result of feeling ignored and unaccepted. Moreover, poor relationship with peers is also one of the risk factors for drug abuse, depression, negative sexual activity, and self-harm behavior (Giletta et al., 2013). Santrock (2014) explained that teenagers tend to feel anxious when they think they are being ignored in a peer environment. The anxiety causes a feeling of rejection by peers (Maner, DeWall, Baumeister, \& Schaller, 2007), which then discourages teenagers from developing and maintaining friendships with such peers.

It is a fact of life that not all teenagers exhibit satisfactory social skills. As an example, the study's subject (S) is a 14-year-old teenage girl who feels unaccepted by her friends and is left out of extracurricular activities at school. She is considered unable to demonstrate the appropriate behavior; hence, she ofen receives a negative response from her friends. She perceives those responses as a form of rejection, which then causes her to have a negative perception of herself. Based on the assessment, subject $S$ lacks three age-appropriate social skills: verbal communication, nonverbal communication, and emotional reactivity. She has troubles maintaining reciprocal communication. She always wants to convey her thoughts and feelings to others, yet often has difficulties listening to others. Her lack of nonverbal communication skills can be observed from her struggle in maintaining eye contact with her interlocutor, that is, she tends to avoid eye contact with the person she is talking to. Moreover, she often displays anger while interacting with friends whom she did not like. She could not control her emotion, which sometimes lead her to punch or yell at her friends. Due to her lack of social skills, social skills training (SST) should be implemented to increase th subkect's verbal and nonverbal communication skills as well as her emotion regulation.

SST is a therapeutic intervention that helps improve social skills, and is based on the application of behavioral and social learning theory and techniques (Nangle, Hansen, Erdley, \& Norton, 2010). SST includes interpersonal skills training, which is taught systematically through modeling by role play, practice, providing constructive feedbacks, and providing assignments to practice the skills learned in real-life situations (Mueser \& Bellack, 2007). The subject would benefit from SST because she has difficulties in communicating and providing the appropriate response while interacting with her peers.

SST was originally developed for children by LeCroy (1982). Following that, Cartwright-Hatton, Tschernitz, and Gomersall (2003) developed SST for teenagers, specifically to reduce social anxiety symptoms by improving communication skills and social competence. Studies indicate that SST is effective in ameliorating social skills in adolescence. Through their six-month research involving129 teenagers, Bellack, Bennet, Gearon, Brown, and Yang (2006) found that SST can improve social skills and reduce the level of addiction. Moreover, a study conducted by Nanyang and Hughes (2002) of 38 teenagers suggested that SST can help increase pro-social behaviors and consequently reduce antisocial behaviors.

Spence is one of the clinicians who applied SST in various adolescence studies. In her studies (2000, 2001, 2003), Spence based her intervention program on five components adolescents' social skills: social behavior skills, social perception skills, self-regulation techniques, social problem-solving skills, and reduction of competing/inhibiting/inappropriate social responses. The last component will only be trained for those with social skills performance deficit, which is a failure to provide an appropriate response to a stimuli due to anxiety. A person with social skills performance deficit has cognitive knowledge of the appropriate response (Spence, 2003) in 
various situations, but is unable to translate such knowledge into actual behavior. SST is usually conducted in a group by involving the significant others of the participants, such as their parents, friends, and teachers, to provide prompts, modeling, and reinforcement.

In this kind of intervention, SST is provided individually where parents are excluded from the training program, but are involved in the generalization process after the intervention is implemented. Teachers are involved as assessors during the assessment as well as during the preand post-test, whereas friends participate as observers to assess the self-regulation component. Peer involvement in the implementation of SST in adolescence can also become an effective method in validating the success of the intervention (Bandy \& Moore, 2011). Through the involvement of teachers and peers in assessing S' social skills at school, we argue that S' social skills can be measured objectively.

\section{Methods}

\section{Participant}

The participant of this study was a 14-year-old female adolescent who visited Klinik Terpadu and exhibited a deficit in social skill. She had negative perception toward herself as friends were rejecting her. She had deficits in the social behavior, social perception, self-regulation technique, and social problem-solving components of social skills. In general, even though she was 14 years old, her social skills were equivalent to those of a 10-year-old child. In the social behavior component, she had deficit in verbal and nonverbal communication. She was able to initiate conversation and communicate her thoughts but did so in an impolite manner, such as using a loud voice in formal (at class) and non-formal settings. As a result of her behavior, $S$ was perceived by her friends as a fierce individual. In terms of nonverbal communication, $\mathrm{S}$ mostly avoided eye contact and had a deficit in understanding others' facial expressions and bodily gestures. She was also unable to initiate appropriate physical contact.

\section{Research Design}

This intervention was conducted with a single-subject design, defined as a study with only one participant (Kumar, 2014). This study used pre- and post-test design, which has been proven to be most appropriate un studying the efficacy of a program (Kumar, 2005). The subject's social skills were measured by her teachers using the Child's Behavior Checklist (CBCL) and Social Skills Questionnaire (SSQ). SSQ measures four aspects of social skills, the improvement of which is the main goal of the intervention. Moreover, self-perception was measured by the SelfPerception Profile for Adolescent (SPPA). The effectiveness of the intervention was measured by the increase of CBCL score (change from borderline range into the normal range), the improvement on SSQ and SPPA scores, observation data, and interviews with the subject's teachers and peers. Furthermore, Session Rating Scales (SRS) and Outcome Rating Scales (ORS) were also employed to measure the subject's motivation or interest in each intervention session. There were three stages in the intervention design: pre-test, intervention session, and post-test. 


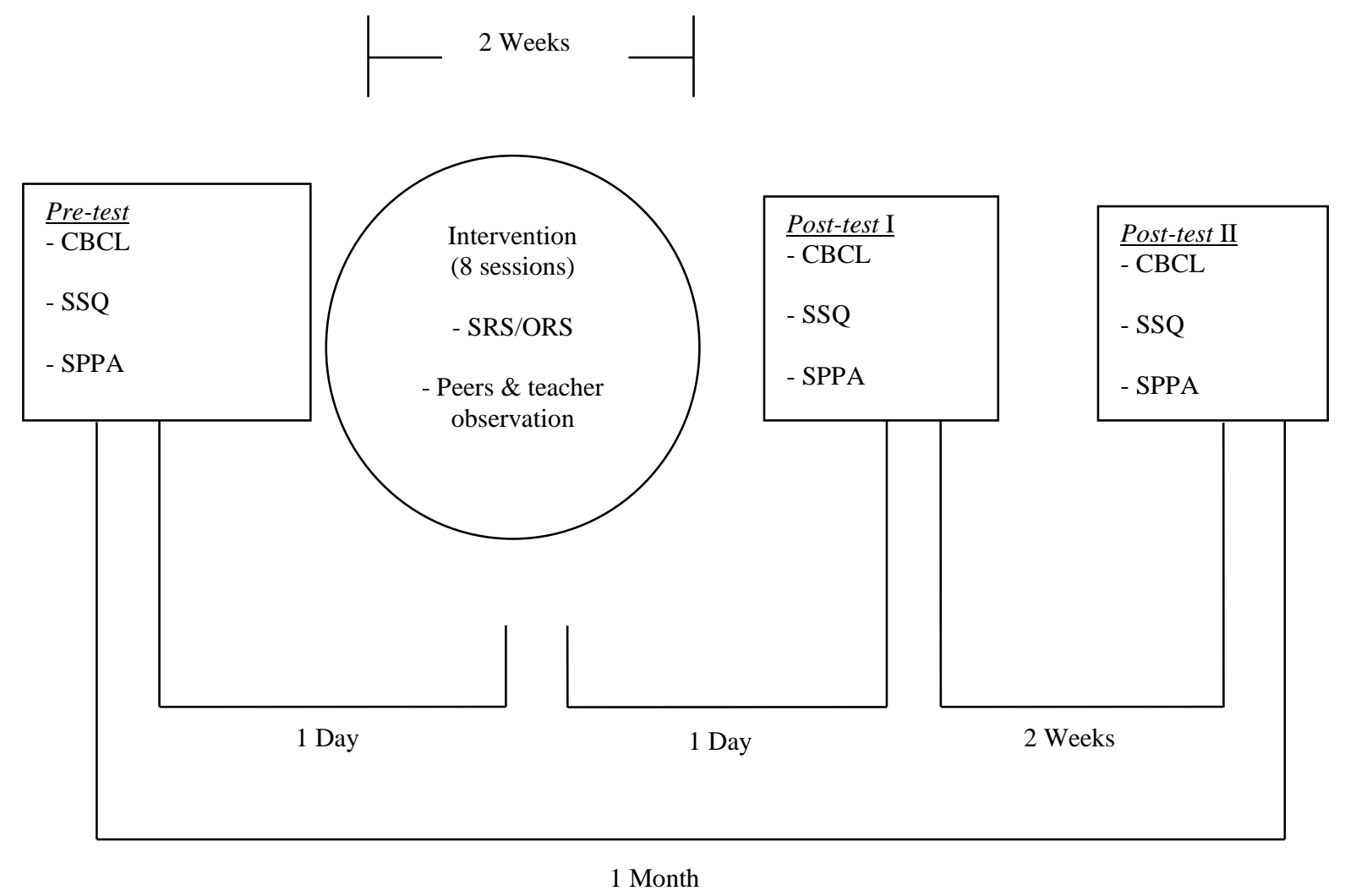

Figure 1. Intervention Design and Procedure

The intervention was completed in eight sessions, each lasting for 30-60 minutes. The intervention was finished in two weeks. According to Spence (2003), an effective intervention for adolescents should be short in duration and delivered in 8-12 sessions. After all the intervention sessions were conducted, post-test I and post-test II were given, and an additional closing session was given. In that session, the parent was informed of the result of the intervention session and was given suggestions to ensure the sustainability of the intervention.

\section{Measures}

The CBCL is employed to identify behavioral and emotional problems as well as child's competence from the parent's point of view (Achenbach, 1991). The Scale consists of two subscales: competence and problem scales. It consists of 113 questions, scored on a three-point Likert scale $(0=$ absent, $1=$ occurs sometimes, $2=$ occurs often $)$. The total score received by a child is compared with the age-norm score and then classified into normal, borderline, or clinical range. Any score that falls below 3.5 is classified as normal, between 3.5-4.25 is borderline, and above 4.25 is considered clinical.

SSQ is designed to measure social skills in 10- to 16-year-old children based on the observations of their teachers and parents (Spence, 2003). Social skills are measured through four components: social behavior skills, social perception skills, self-regulation ability, and social problem-solving skills. This questionnaire consists of 30 items. The subjects are required to rate the extent to which the items best describe his/her social skill for the past four weeks. A previous 
study indicated that the questionnaire has good validity and reliability and tend to be sensitive to the impact of SST.

SPPA is a self-report instrument to measure self-perception in children aged 13-18 years, and consists of nine subdomains: scholastic competence, social competence, athletic competence, physical appearance, job competence, romantic appeal, behavioral conduct, close friendship, and global self-worth (Harter, 2012). In this instrument, participants are asked to rate which kind of child he/she is most likely to be ("Really true for me" or "Sort of true for me").

\section{Procedure}

Prior to the intervention sessions, CBCL and SSQ were administered to the parent and teachers, after which the subject was also requested to fill in the SPPA questionnaire. The pre-test session was conducted a day prior to the intervention session.

Eight sessions were provided to the subject. The first and second sessions were designed to improve the subject's verbal and nonverbal social communication skills, respectively. The third and fourth sessions focused on training emotional understanding about themselves and other people, understanding other people's perception, and providing the appropriate response in different social contexts. The fifth and sixth sessions were targeted for negative emotion regulation and self-control, respectively, and the seventh and eighth sessions were devised for improving social problem-solving skills. Throughout the intervention, several behavioral techniques were used, such as assignments, feedbacks, and modeling, through audio-visual media. Each session lasted anywhere from 30-60 minutes. The description of each session is presented below.

Session I. "Mind My Verbal Expression" was designed improve verbal skills behavior. There were four topics delivered: using appropriate verbal expression and voice volume as well as giving and accepting a compliment. The duration of this session was 60 minutes.

Session II "Your Glance" was targeted to train nonverbal behavior. There were four topics delivered: eye contact, understanding others' facial expressions and bodily gesture, and using appropriate physical touch. The duration was 60 minutes.

Session III "Be Aware of Your Feelings" was targeted to train the subject to recognize her own and others' emotions. It consists of three topics: emotion recognition, feeling temperature, and understanding others' perception. The duration of this session was 45 minutes.

Session IV "My Feeling, Your Feeling" was delivered to improve the subject's understanding of other's emotions and perceptions so that she can manifest the appropriate behavior toward others. This session consisted of one topic, i.e., determining an appropriate response in a daily setting by considering others' feelings and perceptions. The duration was 45 minutes.

Session V "Talk to Yourself" was provided to improve the subject's emotion regulation skill. This session consists of two topics: self-talk and inhibition of inappropriate spontaneous behavior. The duration of this session was 30 minutes. 
Session VI "Think Before You Do" was focused on training the subject's ability to be mindful of her own emotion regulation. This session consists of two topics: self-talk and identification of steps to overcome negative feelings. The session lasted for 30 minutes.

Session VII "Identify the Problem" aimed to improve the subject's social problem-solving skills, and was divided into two topics: problem identification and finding alternative solutions. The duration of this session was 30 minutes.

Session VIII "What Will You Do?" was carried out to improve the subject's social problemsolving skills. There were two topics presented in this session: thinking about the consequences of her own behavior and planning appropriate actions to solve the problems. The duration of this session was 30 minutes.

Table 1

Sessions in the SST Intervention

\begin{tabular}{|c|c|c|c|}
\hline Target Behavior & Session & $\begin{array}{l}\text { Duration } \\
\text { (minute) }\end{array}$ & Method \\
\hline & Assessment & 60 & - \\
\hline & Pre-test & 60 & - \\
\hline Verbal communication & 1 & 60 & Practice, role play, discussion, and feedback \\
\hline Nonverbal communication & 2 & 60 & Practice, role play, discussion, and feedback \\
\hline Understanding her own emotions & 3 & 45 & Practice, discussion, and feedback \\
\hline Understanding others' emotions & 4 & 45 & Practice, discussion, and feedback \\
\hline Emotion regulation & 5 and 6 & 60 & Practice, discussion, and feedback \\
\hline \multirow[t]{4}{*}{ Social problem solving } & 7 and 8 & 60 & Practice, discussion, and feedback \\
\hline & Closing & 60 & - \\
\hline & Post-Test 1 & 60 & - \\
\hline & Post-Test 2 & 60 & - \\
\hline
\end{tabular}

After all the intervention sessions were conducted, a closing session was provided for the parent. In the closing session, the parent was given counseling on how to sustain the impact of the intervention on the subject's social skills. Several suggestions to strengthen the subject's selfconcept and competence were also provided for the parent. The parent was suggested to provide encouragement and reinforcement when the child can control negative feelings and exhibit the ability to solve problems related with peers and social interactions.

\section{Data Analysis}

The target behaviors stated in Table 1 were analyzed by comparing the CBCL, SSQ, and SPPA scores gained in te pre-test, post-test 1 and post-test 2 . In addition, data from the teachers' and peers' observations were analyzed qualitatively.

\section{Results}

The CBCL scores indicated that there was an increase in social competence aspect. In the pretest, the subject's score was in the borderline range (pre-test score $=3$; borderline range $=3-$ 3.25 ), but this slightly improved in post-test I (score $=4$ ) and post-test II (score $=4.25$ ). Therefore, according to the subject's teachers and parent, her social competence improved and become on par with her peers after the intervention was implemented. 


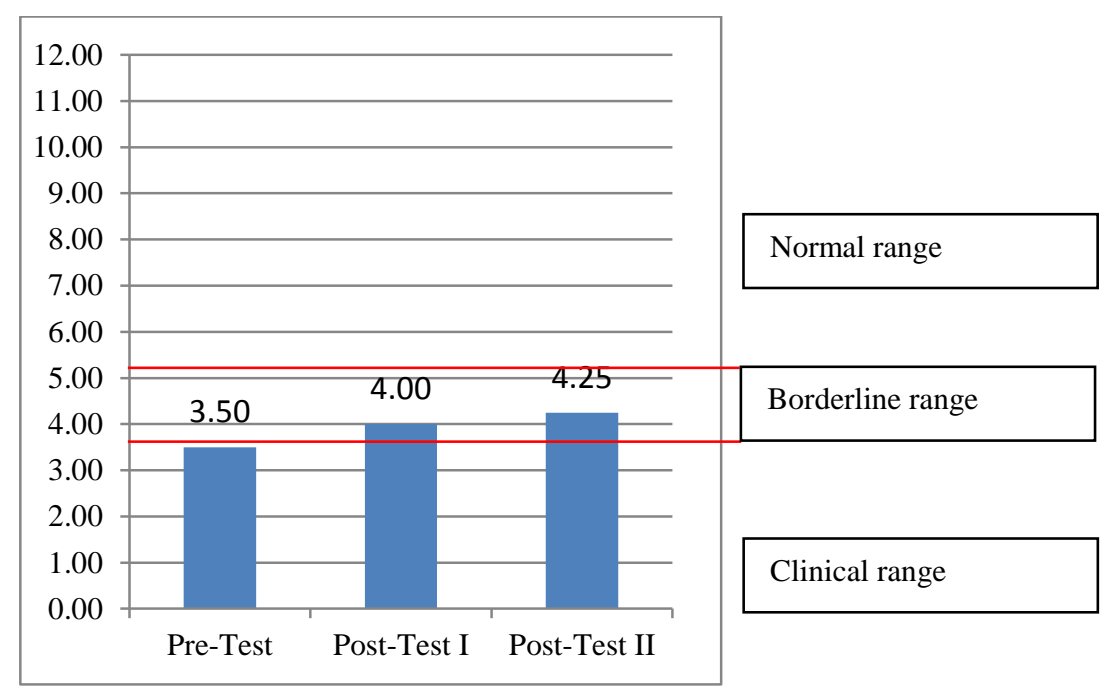

Figure 2. CBCL Scores

Furthermore, there were also an increase in four domains of SSQ. As shown in Figure 2, S' overall social skills improved and passed the average score of her peers (average scores in the pre-test $=2.38$, post-test $1=2.65$, post-test $2=2.98$, and norm age $=2.88$ ) .

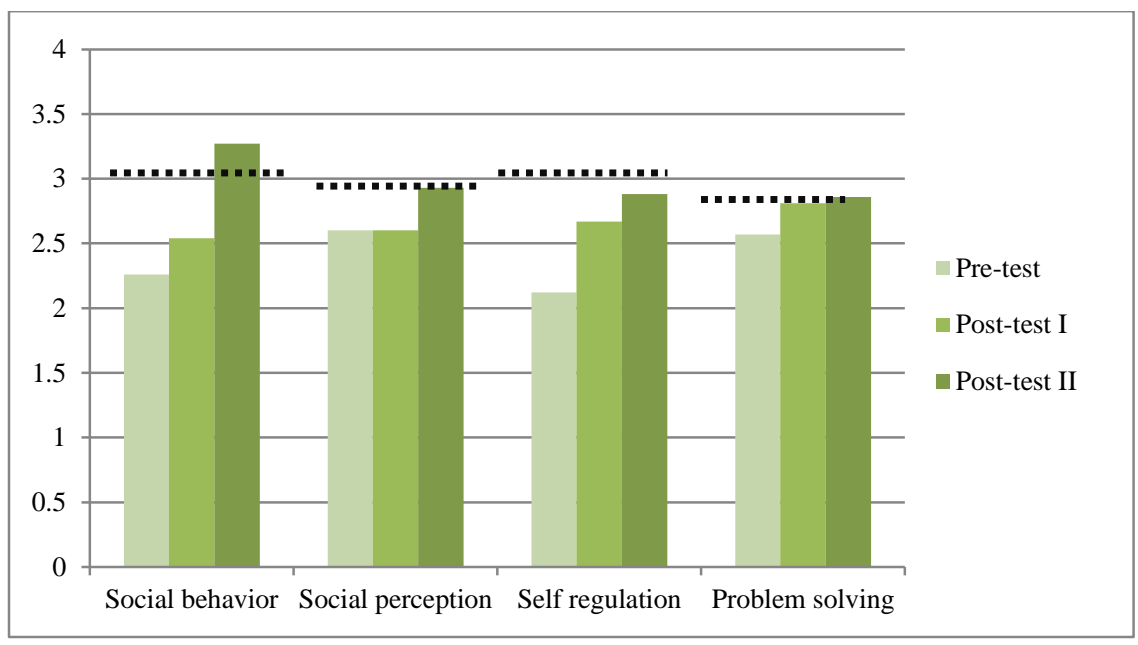

Figure 3. SSQ Scores. The dotted lines indicate the average scores for adolescents.

Based on the SPPA questionnaire, there were improvements in physical appearance, social competence, close friendship, and global self-worth scores (Figure 4). Taking the social competence domain for example, it increased from 2.4 in the pre-test to 3.8 and 4.0 in the posttest 1 and post-test 2, respectively. These results indicate an improvement in S' self-perception regarding her social competence after the SST was delivered. Moreover, S' own perception of her physical appearance was also ameliorated (pre-test $=1$, post-test $1=2.2$, post-test $2=3$ ). 
Before the intervention was given, $S$ perceived herself as physically unattractive, and became more comfortable with her looks after she received the training.

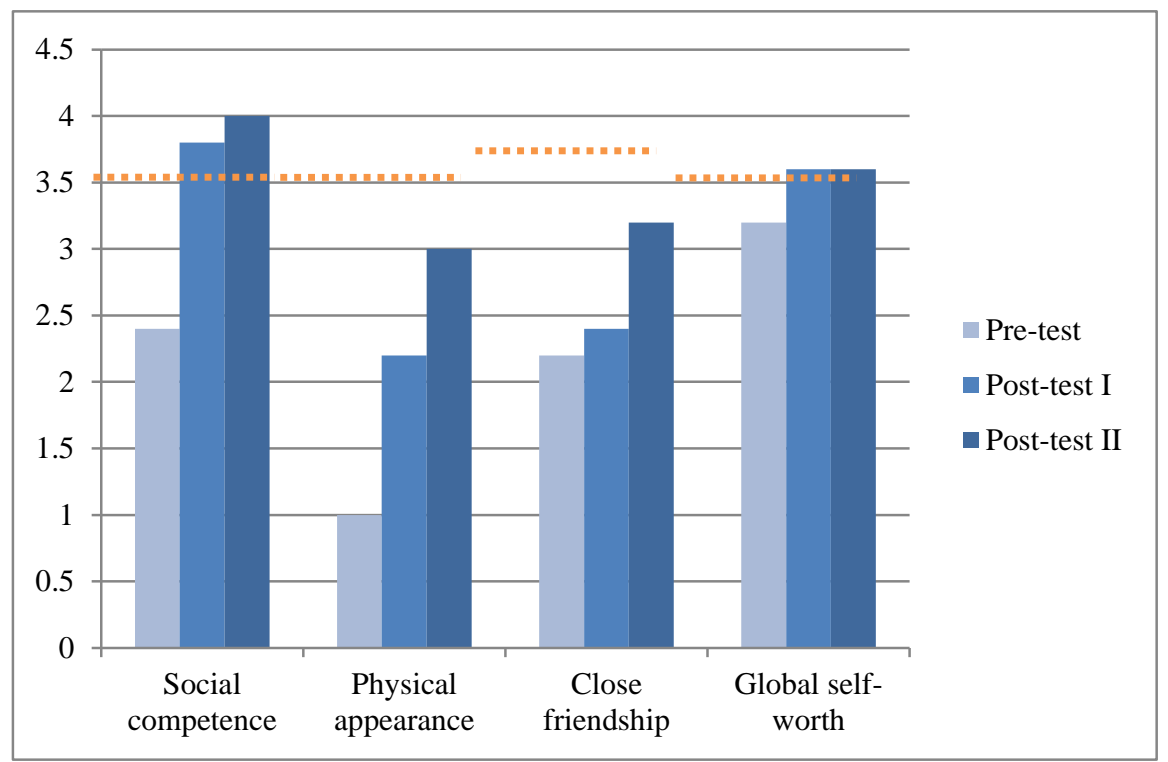

Figure 4. SPPA Scores. The dotted lines indicate the normal range for female adolescents.

After the intervention was conducted, there was an increase in the close friendship sub-domain based on the SPPA questionnaire (pre-test $=2.2$, post-test $1=2.4$, post-test $2=3.2$ ). Before the intervention, $\mathrm{S}$ had a rather negative perception about her relationship with close friends, but this became more positive after the intervention. Additionally, the subject's global self-worth scores also improved slightly (pre-test $=3.2$, post-test $1=3.6$, post-test $2=3.6$ ). Based on those scores, the subject's self-worth improved slightly after the intervention and such an improvement was sustained until after post-test 2.

Qualitative measures were also conducted through peers' and teachers' interviews and observations. The subject's teachers and peers reported that $\mathrm{S}$ exhibited less inappropriate behaviors and uttered less offensive words when interacting with her friends at school. However, she still used several impolite words while interacting with friends in a less formal situation (e.g., during the recess), although her friends no longer felt disturbed. Moreover, her teachers also informed us that the subject demonstrated better nonverbal communication skills. She stopped hitting her friends, stopped talking when the interlocutors displayed negative facial expressions, and maintained eye contact with appropriate duration and intensity.

Furthermore, during the intervention, the subject was able to identify different emotions and tried to respond appropriately according to the interlocutor's various emotional expressions. Her teachers observed that $S$ had exerted effort to initiate interactions with friends she was not previously close with. To reduce inappropriate behaviors, $\mathrm{S}$ also changed her negative thoughts into positive ones through self-talk and practice, which were part of the emotional regulation ability. According to her teacher, after the intervention, S' negative comments and inappropriate spontaneous behaviors were noticeably reduced. The teachers also stated that $\mathrm{S}$ demonstrated 
good social problem-solving skills. However, $S^{\prime}$ friends reported that $S$ still talked loudly in several occasions.

\section{Discussion}

The intervention was conducted to improve the social skills of a 14-year-old girl. In line with the findings published by Nanyang and Hughes (2012) and Spence (2003), the SST was effective in improving S' social skills. The improvements in verbal and nonverbal communication skills were reported by $S^{\prime}$ friends and teachers.

In addition to the teachers' and peers' interview comments and observations, the positive impact of the training was also demonstrated by the high scores in SSQ obtained by the subject. S' selfperception was improved markedly after the intervention was delivered. Before participating in the training, $\mathrm{S}$ felt that she was not capable of communicating with friends, was not accepted, nor did she feel comfortable in forging interpersonal relationships with her peers. She also had a negative perception of her physical appearance. According to Harter (2012), in early adolescence (13- to 15-year-olds), self-perception is closely related to social skills and could affect one's interactions with other people. Hence, having positive self-perception encourages someone to initiate more social interactions with their friends and surroundings.

There are three things that support the effectiveness of this intervention. First is the accurate assessment to identify the social skills deficit problem and behavioral target to set the appropriate intervention goal. In planning the intervention, we conducted a thorough assessment to identify social behavior components that need to be trained in the home, social, and peer-relation contexts based on information gathered from the subject's parents, friends, and teachers. This informationgathering process is in accordance with Spence (2003) who suggested that during the assessment, information must be collected from several settings and informants, including one's home, school, and peers. By performing a comprehensive assessment, target behaviors can be set properly, thus a suitable targeted intervention can be planned.

The second factor is the subject's active participation and persistence in each session, as well as her willingness in doing all of the homework given. The data obtained from SRS and ORS showed that $\mathrm{S}$ felt the intervention sessions were delivered according to her needs, which encouraged her to follow all sessions earnestly. Her strong motivation and cooperation helped us achieve each session's goal. Indeed, motivation has been mentioned as one of the most important factors that could determine the success of an intervention (Cartledge \& Milburn, 1995).

The third factor is the involvement of several people (teachers, close friends, and parents) to help $\mathrm{S}$ apply what has been learned in intervention sessions into everyday situations. In SST, the involvement of people around them can help participants practice skills in natural situations. The involvement of people closest to the participants is vital in the assessment and evaluation process and in the provision of constructive feedback (Spence, Donovan, \& Brechman-Toussaint, 2000; Spence, 2000). In line with Spence's statement, Bulkeley (1991) also reported that teacher engagement is considered effective in generalizing the social skills that have been trained in natural situations in which adolescents usually interact. 
Despite its success, this training also has three weaknesses. First, the emotional regulation exercises were given twice in the same day. Therefore, additional self-regulation sessions are needed so that $\mathrm{S}$ can manage negative emotions better. Second, although we measured selfesteem and self-perception through SPPA in this study, we did not investigate the increase in academic achievement and the improvement in peer interaction because of time constraints. The intervention was conducted during school holiday; therefore, data regarding academic achievement and peer interactions were not available. The improvements in social skills should increase self-esteem (Mize, 1005) and self-perception (Furman \& Buhrmmester, 1992), as well as positive peer relationship and academic achievement at school (Caprara, et al., 2000). Hence, it would be interesting to see whether the subject's peer relationship and academic achievement also improved after the training.

\section{References}

Bandy T., Moore K. A. (2011). What works for promoting and enhancing positive social skills: Lessons from experimental evaluations of programs and interventions. Child Trends Fact Sheet, 2011-07.

Bellack, A. S., Bennet, M. E., Gearon, J. S., Brown, C. H., \& Yang, Y. (2006). A randomized clinical trial of a new behavioral treatment for drug abuse in people with severe and persistent mental illness. Archives of General Psychiatry, 63, 426 432.

Bulkeley, R. (1991). Social skills training with young adolescent: Group and individual approaches in school setting. Doctoral thesis. London: Loughborough University.

Caprara, G. V., Barbaranelli, C., Pastorelli, C., Bandura, A., \& Zimbardo, P. G. (2000). Prosocial foundations of children's academic achievement. Psychological Science, 11 (4), 302-306.

Cartledge, G., \& Milburn, J. F. (1995). Teaching social skills to children: Innovative approaches (2nd ed.). New York, NY: Pergamon.

Cartwright-Hatton, S., Tschernitz, N., \& Gomersall, H. (2003). Social anxiety in children: social skills deficit, or cognition distortion? Behavior Research and Therapy, 43, 131-141.

Furman, W., \& Buhrmester, D. (1992). Age and sex differences in perceptions of networks of personal relationships. Child Development, 63, 103-115.

Giletta et al. (2013). Direct and indirect peer socialization in adolescent non-suicidal self-injury. Journal of Research and Adolescence, 23 (3), 450-463.

Gottman, JM., \& Parker, JG. 1987. Conversations of friends: Speculations on affective development. New York, NY: Cambridge University Press.

Haager. M., \& Vaughn. S. (1995). Parent, teacher, peer, and self-reports of the social competence of students with learning disabilities. Exceptional Children, 67, 331-344.

Harter, S. (2012). Self-perception profile for adolescents: Manual and questionnaires. Denver CO: University of Denver.

Harter, S. (2012). The construction of the self: Developmental and cultural foundations. New York, NY: The Guilford Publications.

Ingersoll, G. M. (1989). Adolescents (2 $2^{\text {nd }}$ ed.). Englewood Cliffs, NJ: Prentice Hall.

Kingery, J. N., Erdley, C. A., \& Marshall, K. C. (2011). Peer Acceptance and Friendship a Predictors of Early Adolescents' Adjustment Across the Middle School Transition. Journal of Developmental Psychology, 57, 215-243.

Kolb, S. M. \& Hanley-Maxwell, C. (2003). Critical social skills with adolescents with high incidence disabilities: Parental perspectives. Council for Exceptional Children, 69 (2), 163-179.

Kumar, R. (2014). Research methodology: A Step-by-step guide for beginners (4th ed.). Thousand Oaks, CA: Sage Publications.

LaGreca, A. M., \& Harrison, H. M. (2005). Adolescent peer relations, friendships, and romantic relationships: Do they predict social anxiety and depression? Journal of clinical child and adolescent psychology, 34 (1), 49-61.

LeCroy, C. W. (1982). Teaching social skills to children in the schools. In J. P. Flynn and R. Constable (Eds.), School Social Work: Practice, Research and Theory. Homewood, IL: Dorsey Press.

Maner, J. K, DeWall, C. N., Baumeister, R. F., \& Schaller, M. (2007). Does social exclusion motivate interpersonal reconnection? Resolving the "Porcupine Problem". Journal of Personality and Social Psychology, 92 (1), 42-55.

Mize, J. (2005). Social skills intervention and peer relationship difficulties in early childhood: In. R. E. Tremblay., R. G. Barr., R. DeV. Peters (Eds.). Encyclopedia on Early Childhood Development [online]. Montreal, Quebec: Centre of Excellence for Early Childhood Development.

Mueser, K. T., \& Bellack, (2007). Social skills training: alive and well? Journal of Mental Health, 16 (5), 549-552. 
Nangle, D.W., Hansen, D.J., Erdley, C.A., \& Norton, P.J. (2010). Practitioner's guide to empirically based measures of social skills. New York, NY: Springer.

Nanyang, R. P., \& Hughes, J. N. (2002). Differential benefits of social skills training with antisocial youth based on group composition: A meta-analytic investigation. School Psychology Review, 31, 164-185.

Papalia, D. E., \& Martorell, G. (2014). Experience human development (13rd ed). New York, NY: McGraw-Hill.

Santrock, J. W. (2014). Adolescence (15 ${ }^{\text {th }}$ ed.). New York, NY: McGraw-Hill.

Spence, S. H., \& Donovan, C. (1998). Interpersonal problems. In P. J. Graham (Ed.). Cognitive behaviour therapy for children and families (pp. 217-245). New York, NY: Cambridge University Press.

Spence, S. H., Donovan, C., \& Brechman-Toussaint, M. (2000). The treatment of childhood social phobia: The effectiveness of a Social Skills Training-based, cognitive-behavioural intervention, with and without parental involvement. Journal of Child Psychology and Psychiatry and Allied Disciplines, 41, 713-726.

Spence, S. H., Barret, P. M., \& Turner, C. M. (2001). Psychometric properties of the Spence children's anxiety scale with young adolescents. Anxiety Disorders, 17, 605-625.

Spence, S. H. (2003). Social skills training with children and young people: Theory, evidence, and practice. Child and Adolescent Mental Health, 8 (2), 84-96.

Steinberg, L. (2008). A social neuroscience perspective of adolescent risk-taking. Developmental Reviews, 28 (1), 78-106.

Sugai, G., \& Lewis, T. J. (1996). Preferred and promising practices for social skills instruction. Focus on Exceptional Children, $29(4), 1-16$

Wentzel, K. R., McNamara, B. C., \& Caldwell, K. A. (2004). Friendships in middle school: Influences on motivation and school adjustment. Journal of Educational Psychology, 96 (2), 195-203. 